Виі. 1, 2019

\title{
для дискУсії
}

УДК 621.316.925

\author{
В. Й. Чабан \\ Національний університет “Львівська політехніка", \\ кафедра теоретичної та загальної електротехніки, \\ vtchaban@polynet.lviv.ua \\ Б. І. Крохмальний \\ Національний університет “Львівська політехніка", \\ bohdan.i.krokhmalnyi@1pnu.ua
} кафедра електромехатроніки та комп’ютеризованих електромеханічних систем ,

\section{СИНГУЛЯРНІ ПРОБЛЕМИ В ЗАДАЧАХ ЕЛЕКТРИКИ І МЕХАНІКИ ЗА ІДЕАЛІЗАЦІї МАТЕМАТИЧНОГО ОПИСУ}

https://doi.org/10.23939/sepes2019.01.092

(C) Чабан В. Й., Крохмальний Б. І., 2019

Показано можливі небезпеки ідеалізації під час побудови математичних образів фізичних об'сктів чи систем. Вони можуть бути прийнятні, приховані, або навіть такі, що сягають сингулярности, а то й нереальні. Це розкрито на п'ятьох практичних задачах електрики і механіки. Зокрема, йдеться про електричні кола, що містять $E J$-вироджені перетини й контури, утворені виключно ідеальними джерелами струму i ЕРС, про обертову сингулярність за ідеальної пружности, про гармонічний електричний резонанс, про зовнішню характеристику серіссного генератора постійного струму за ідеального феромагнетизму, про сигулярність і парадокс $4 / 3$ електрона. Повна система рівнянь електричного кола завше містить кількість рівнянь, що дорівнює кількості невідомих. Але якщо є перетини, утворені виключно ідеальними джерелами струму $j$, або контури, утворені виключно ідеальними джерелами напруги $e$, то вона стає недовизначеною, бо рівняння, складені за законами Кірхгофа для таких перетинів і контурів (надалі називатимемо їх ЕЈ-виродженими), не містять невідомих, хоч самі закони повинні суворо дотримуватись.

Такі задачі доволі часто виникають на практиці: достатньо назвати трифазне коло, ідеальні джерела напруги якого з'сднано трикутником, або ідеальні джерела струму - у зірку. Але найчастіше $E J$ - виродження виникають у задачах аналізу радіоелектронних кіл.

Наукові пошуки часто натрапляють на практичні задачі, розв'язки яких надто спрощуються за умов тієї чи иншої локальної ідеалізації, а то й неможливі без неї. Тому треба відповідально ставитися до аналізу одержаних результатів у кожному конкретному випадку. Задачі на сингулярність були розглянуті лише в тому розумінні, аби загострити проблему. 
Будь-який математичний образ реального фізичного процесу здійснюється за тих чи инших логічних припущень, зокрема й ідеалізації.

Але ідеалізацією треба користуватися розсудливо, бо вона може призводити до разючих спотворень істини, у граничних випадках навіть до сингулярности, як показано нижче, а інколи до малопомітних, а тому найпідступніших.

Ключові слова: ідеалізація; синуулярність; ЕЈ-вироджені кола; обертова сингулярність; гармонічний електричний резонанс; серієсний тенератор постійного струму; безконфліктний електрон.

\section{Постановка проблеми}

У роботі показані проблеми, явні або приховані, які можуть виникати у процесі творчої ідеалізації під час розроблення математичних образів фізичної реальности в тій чи иншій формі.

\section{Актуальність дослідження}

Існує широке коло практичних задач, для успішного розв'язання яких ми змушені звертатися до ідеалізації того чи иншого фізичного процесу. В одних випадках такий захід дає цілком прийнятні для практики результати, в инших він провадить до малопомітних підступних результатів, а в граничних випадках - навіть до сингулярности, цілком логічної, а то й до абсурдної. Тому акцентувати на таких перешкодах у творчих вправах завше на часі.

\section{Формулювання мети та завдань статті}

Мета статті - звернути увагу дослідника тих чи иншіх фізичних об’єктів чи систем на можливі загрози для істинности отриманих результатів 3-за тієї чи иншої ідеалізації.

\section{Аналіз останніх досліджень і публікацій}

Системних наукових досліджень на цю тему в доступній нам літературі не виявлено. У творчому пошуку цей процес витіснено на поле підсвідомости.

\section{Виклад основного матеріалу}

\section{Розв'язання рівнянь за вироджень ідеальних джерел енергії}

Повна система рівнянь електричного кола завше містить кількість рівнянь, що дорівнює кількості невідомих. Але якщо є перетини, утворені виключно ідеальними джерелами струму $j$, або контури, утворені виключно ідеальними джерелами напруги $e$, то вона стає недовизначеною, бо рівняння, складені за законами Кірхгофа для таких перетинів і контурів (надалі називатимемо їх $E J$-виродженими)

$$
\begin{gathered}
\sum_{k} j_{k}=0 \\
\sum_{k} e_{k}=0
\end{gathered}
$$

не містять невідомих, хоч самі закони повинні суворо дотримуватись.

За наявності $E J$-вироджень необхідні й достатні умови Кронекера-Копеллі сумісности повної системи рівнянь кола не порушуються, що допускає наявність у них розв'язку. Але оскільки детермінант системи дорівнює нулю, то ця задача належить до некоректних і іï розв'язування потребує застосування громіздких методів регуляризації [1], суть яких зводиться до введення в діагональні елементи матриці деяких чисел, тоді їі детермінант стає відмінним від нуля, а це усуває проблему розв'язування. Сдиність розв'язку досягається тим, що ці числа вибирають не довільно, а так, щоб сферична норма невідомих була мінімальною. Тоді розв'язок називається нормальним.

Але виявляється, що в теорії електричних кіл нормальний розв'язок можна отримати значно простіше, усунувши проблему ще на стадії формування рівнянь стану. Для цього в [2] доведемо дві важливі теореми, пов'язані з отриманням нормального розв'язку. 


\section{В. Й. Чабан, Б. І. Крохмальний}

Теорема 1. У ЕЈ-виродженому контурі алгебраїчна сума струмів джерел напруги дорівнює нулю

$$
\sum_{k} i_{k}=0
$$

де $i_{\kappa}-$ струм $\kappa$-го джерела напруги.

Кожний зі струмів $i_{\kappa}$, обчислений за (3), завжди можна подати алгебраїчною сумою струму джерела, що виникає у разі розриву $E J$-виродженого контуру, й деякого зрівнювального струму $i$, що добре узгоджується із фізикою процесу. Причому зрівнювальний струм установлюється таким, щоб сферична норма невідомих була мінімальною

$$
\sum_{\hat{e}} i_{k}^{2}=\min
$$

Теорема 2. У ЕЈ-виродженому перетині алтебраїчна сума напруг джерел струму дорівнює нулю

$$
\sum_{\hat{e}} u_{j k}=0
$$

де $u_{j \kappa}$ - напруга $\kappa$-го джерела струму.

Умова (5) також забезпечує мінімальну норму невідомих

$$
\sum_{\kappa} u_{j k}^{2}=\min .
$$

Отже, щоб отримати нормальний розв'язок рівнянь стану електричного кола, треба в $E J$-вироджених перетинах і контурах структурні рівняння (1), (2), складені за законами струмів і напруг Кірхгофа, замінити інверсними їм рівняннями (3), (5).

$E J$-вироджені перетини та контури виникають лише в ідеалізованих моделях джерел енергії, тому розв'язання невизначености рівнянь стану кола можна або досягти переходом до реальних джерел енергії, або знайти згідно із запропонованими методом нормальні розв'язки.

Подібні задачі доволі часто виникають на практиці: достатньо назвати трифазне коло, ідеальні джерела напруги якого з'єднані трикутником, або ідеальні джерела струму - в зірку. Але найчастіше $E J$-виродження виникають у задачах аналізу радіоелектронних кіл!!!

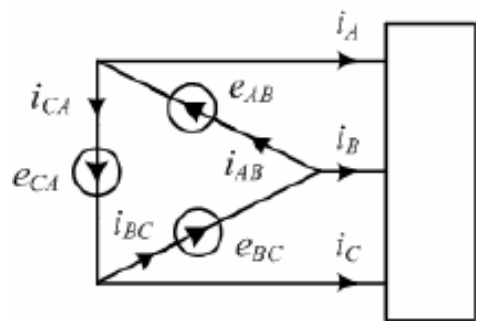

Рис. 1. Схема ЕЈ-виродже-ного трифазного елект-ричного кола

Приклад. На рис. 1 зображено схему трифазного кола, що містить $E J$-вироджений контур ідеального трифазного генератора. Лінійні струми отримані з попереднього аналізу, тому вважаються відомими. Треба обчислити фазні струми генератора.

Для цього складаємо систему рівнянь за законом струмів Кірхгофа:

$$
i_{A B}-i_{C A}=i_{A} ; \quad i_{B C}-i_{A B}=i_{B},
$$

а замість рівняння (2) використаємо (3)

$$
i_{A B}+i_{B C}+i_{C A}=0 .
$$

Розв'язавши систему (7), (8), отримаємо:

$$
i_{A B}=\left(i_{A}-i_{B}\right) / 3 ; \quad i_{B C}=\left(i_{B}-i_{C}\right) / 3 ; \quad i_{C A}==\left(i_{C}-i_{A}\right) / 3 \text {. }
$$

Зауважимо, що лінійні струми підпорядковані закону струмів Кірхгофа.

А при чому тут сингулярність? Відповідь така. В $E J$-виродженому контурі можлива поява деякого зрівнювального струму $i$, який накладається на кожний зі струмів $i_{\kappa}$. Розбалансу струмів $i_{\kappa}$ инакше досягти неможливо, не порушуючи законів Кірхгофа в суміжних вузлах. В $E J$-виродженому перетині можлива поява такої ж напруги $u$. Отой струм $\mathrm{i}$ ота напруга можуть набувати будь-яких значень, сягаючи навіть сингулярности, не порушуючи ніяких законів теоретичної електротехніки.

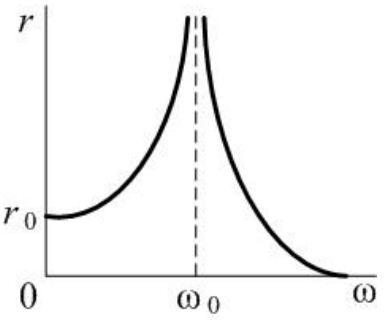

Рис. 2. Залежність $r(\omega)$ обертової маси 


\section{Обертова сингулярність}

На основі універсальної формули протоенергії [3] запишемо вираз кінетичної коенергії [4] у відповідному вигляді

$$
w_{k c}=\int_{0}^{\mathbf{v}} m(\mathbf{v}) \mathbf{v}, d \mathbf{v},
$$

де $m$ - статична маса; $\mathbf{v}$ - вектор лінійної швидкости.

Оскільки $v=\omega r$, де $\omega, r$ - кутова швидкість і радіус центра мас обертового тіла, вираз (10) набуває вигляду

$$
w_{k c}=\int_{0}^{\omega r} m \omega r d(\omega r)=\frac{m \omega^{2} r^{2}}{2}=J \omega^{2}
$$

де $J$ - момент кількости руху.

Відцентрову силу можна знайти за градієнтом кінетичної енергії

$$
f=\frac{\partial}{\partial r} \frac{m \omega^{2} r^{2}}{2}=m \omega^{2} r
$$

Приклад. Розглянемо обертовий рух масивної кулі на пружинній розтяжці. Кінетичну коенергію кулі знаходитимо за (11), а потенціальну як

$$
w_{p}=\int_{0}^{r-r_{0}} c x d x=\frac{1}{2} c\left(r-r_{0}\right)^{2},
$$

де $c$ - коефіцієнт штивности ідеального матеріалу розтяжки.

Нехтуючи дисипацією енергії, виразимо дію як [3, 4]

$$
L=w_{k c}-w_{p}
$$

Баланс сил знайдемо як варіацію (14)

$$
\frac{\partial L}{\partial r}=\frac{\partial}{\partial r}\left[\frac{m \omega^{2} r^{2}}{2}-\frac{c\left(r-r_{0}\right)^{2}}{2}\right]=m \omega^{2} r-c\left(r-r_{0}\right)=0 .
$$

На підставі (15) одержуємо остаточне рівняння руху

$$
r(\omega)=\bmod \frac{c r_{0}}{c-m \omega^{2}} .
$$

Підставляючи (16) у (12), одержуємо вираз сили

$$
f(\omega)=\bmod \frac{m c r_{0}}{c / \omega^{2}-m} .
$$

Сили дисипації перебувають у квадратурі із рештою сил. Під час переходу до бездисипативних систем у (16) і (17) засвітиться математична операція $\sqrt{x^{2}}=\bmod x$, важлива для трактування реального процесу!

Цікавий стан настає за умови: $\omega=\omega_{0}$, де

$$
\omega_{0}=\sqrt{c / m}
$$

пов'язаний із сингулярністю сили й радіуса.

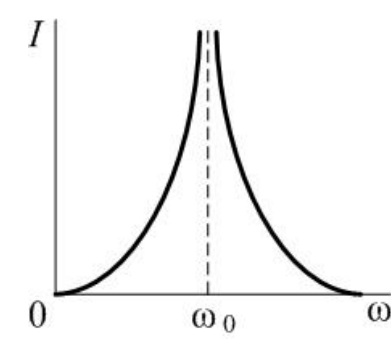

Рис. 3. Залежність $I(\omega)$ в безвтратному послідовному $L-C$-колі

3 якісного аналізу функцій (16), (17) отримуємо

$$
\begin{aligned}
& \left.r\right|_{\omega=0}=r_{0} ;\left.\quad r\right|_{\omega=\omega_{0}}=\infty ;\left.\quad r\right|_{\omega>\omega_{0}}<? . \\
& \left.f\right|_{\omega=0}=0 ;\left.\quad f\right|_{\omega=\omega_{0}}=\infty ;\left.\quad f\right|_{\omega>\omega_{0}}<? .
\end{aligned}
$$




\section{В. Й. Чабан, Б. І. Крохмальний}

У діапазоні $0 \leq \omega \leq \omega_{0}$ йдеться про майже реальний процес, а у діапазоні $\omega \geq \omega_{0}$ - про надреальний стан (?), причому надзвичайно цікавий. Звичайно, про нескінченні розміри в дисипативних системах йтися не може. Графічну інтерпретацію (16) показано на рис. 2.

Гармонічний електричний резонанс

Під цим кутом зору цікаво зіставити електричну аналогію ідеального резонансу напруг в разі послідовного з'єднання котушки індуктивности й конденсатора. Вигляд виразу діючого (середньоквадратичного) значення струму як функції циклічної частоти живлення відомий

$$
I(\omega)=\bmod \frac{U}{\omega L-1 / \omega C},
$$

де $U, I$ - діючі значення напруги живлення і струму; $L, C$ - індуктивність котушки та ємність конденсатора.

Резонансну частоту знаходимо за нульового значення знаменника

$$
\omega_{0}=\frac{1}{\sqrt{L C}} .
$$

Графічну інтерпретацію (20) показано на рис. 3.

\section{Зовнішня характеристика серіссного генератора постійного струму}

У генераторах послідовного збудження якір з'єднаний з обмоткою збудження послідовно, тому струм навантаження є водночас струмом якоря і струмом збудження. Обмотку збудження такої машини виготовлено з провідників, розрахованих на струм якоря. Кількість витків такої обмотки мала. На холостому стані генератора ЕРС в обмотці якоря індукується лише залишковим магнетизмом, значить, у такого генератора характеристика холостого стану відсутня, а також регулювальна характеристика. Рівняння зовнішньої характеристики одержуємо за [5]

$$
U=c_{E} n \Phi-r_{a} I_{a},
$$

де $U, \Phi, I_{a}$ - напруга, основний магнетний потік і струм якоря; $n=c o n s t-$ кількість обертів за секунду; $r_{a}$ - сумарний опір кола якоря; $c_{E}-$ сталий конструкційний коефіцієнт.

Зв'язок магнетного потоку Ф зі струмом збудження $I_{f}$ виразимо у вигляді ідеального феромагнетизму (ненасиченого магнетопроводу)

$$
\Phi=\lambda I_{f},
$$

де $\lambda$ - коефіцієнт ідеальної пропорційности.

За умови, що $I_{f}=I_{a}$, і появи в колі якоря опору обмотки збудження $r_{f}$, рівняння (22) набуде вигляду

$$
U=a I_{a},
$$

де

$$
a=c_{E} n \lambda-\left(r_{a}+r_{f}\right)=\text { const. }
$$

Отже, за ідеального феромагнетизму вираз (24) є рівнянням прямої, що проходить через початок координат під нахилом (25). Насправді зі збільшенням насичення феромагнетика сповільнюється зростання першого доданка, а другий зростає пропорційно до $I_{a}$, у результаті чого характеристика (24) набуває реального вигляду. За умови ідеалізації феромагнетизму приходимо до генератора сингулярної потужности, а отже, його напруги і струму.

\section{Сингулярність точковости електрона}

Донедавна моделі електрона були притаманні дві проблеми - парадокс 4/3 і сингулярність точковости: енергії та маси. Маса електрона, отримана 3 імпульсу електромагнетного поля і за універсальною формулою $m=E / c^{2}$, відрізнялися в $4 / 3$ разу, а за спрямування радіуса частинки 
$r \rightarrow 0$ енергія сягала сингулярности. Обидві проблеми були зняті, коли ми, на подобу чорної діри в гравітації, ввели електричну білу діру з електричним радіусом $r_{e}=1,183487 \cdot 10^{-15}$ м і прийняли кварковий розподіл густин ладунку в трьох активних зонах однакового об'єму за радіусом $r:-e 2 / 3,-e 2 / 3$, $+e 1 / 3$ [2]. Цікаво, що значення $r_{e}$ було передбачене як $r_{e}=\sqrt[3]{1 / 4} a$, де $a$ - радіус електрона, лише на основі гармонії кваркових сфер, а потім підтверджене розв'язком відповідного нелінійного рівняння 6-го порядку! Сингулярність тут знімається в очевидний спосіб - радіус не може переступити межі $r \geq r_{e}$. За радіус білої діри доступ електричним ладункам заборонений, тому закони електрики там зазнають колапсу, подібно як закони гравітації у чорній.

\section{Висновок}

Будь-який математичний образ реального фізичного процесу будується за тих чи инших логічних припущень, зокрема ідеалізації. Але ідеалізацією треба користуватися розсудливо, бо вона може призводити до разючих спотворень істини, у граничних випадках навіть до сингулярности, як показано вище, а інколи до малопомітних, а тому найпідступніших.

\section{Перспективи подальших досліджень}

Наукові пошуки часто натрапляють на практичні задачі, розв'язки яких надто спрощуються за умов тієї чи иншої локальної ідеалізації, а то й неможливі без неї. Тому треба відповідально ставитися до аналізу одержаних результатів у кожному конкретному випадку. Задачі на сингулярність ми розглянули лише в тому розумінні, аби вказати на цю проблему.

\section{Список використаних джерел}

1. Тихонов А. Н., Арсенин В. Я. Методы решения некорректных задач. М.: Наука, 1974. 223 с.

2. Чабан В. Електромагнетні процеси. Львів: Простір М., 2017. 412 с.

]. Чабан В. Протоенергія // Технічні вісті (Technical News). 2016/1(43), 2 (44), c. 12-13.

4. Чабан А. Математичне моделювання коливних процесів у електромеханічних системах. Львів: Вид-во Тараса Сороки, 2008. 328 с.

5. Чабан В. Електротехніка. Луцьк - Львів, 2013. 252 с.

\section{References}

1. Tykhonov A. N., Arsenyn V. Ya. Metody resheniya nekorektnykh zadach. M.: Nauka, 1974. 223 s.

2. Chaban V. Elektromahnetni protsesy. L.: Prostir M., 2017. $412 \mathrm{s.}$

3. Chaban V. Protoenercia // Tekhnichni visti (Technical News) 2016/1(43), 2 (44), s. 12-13.

4. Chaban A. Matematychne modeliuvnnia kolyvnykh protsesiv u elektromekhanichnykh systemakh. L.: Vyd-vo Tarasa Soroky, 2008. 328 s.

5. Chaban V. Elektrotekhnika. Lutsk - Lviv, 2013. $252 \mathrm{s.}$ 


\author{
V. Yo. Chaban \\ Lviv Polytechnic National University, \\ Department of Theoretical and General Electrical Engineering, \\ vtchaban@polynet.lviv.ua
}

\author{
B. I. Krokhmalnyy \\ Lviv Polytechnic National University, \\ Department of Electromechatronics and Computerized Electromechanical Systems, \\ bohdan.i.krokhmalnyi@lpnu.ua
}

\title{
SINGULAR PROBLEMS IN ELECTRIC AND MECHANICS TASKS AT IDEALIZATION MATHEMATICAL DESCRIPTION
}

\section{(C) Chaban V. Yo., Krokhmalnyy B. I., 2019}

The possible dangers of idealization in the process of constructing mathematical images of physical objects or systems are shown. The above is revealed on five practical problems of electricity and mechanics. They may be acceptable, hidden, or even such as reaching singularities, or even unreal. It is revealed on five practical problems of electricians and mechanics.

In particular, it is a question of electric circuits containing EJ-degenerate sections and circuits formed solely by ideal current sources and EMFs, rotational singularity for ideal elasticity, harmonic electrical resonance, external characteristic of a serial steady state generator for the ideal ferromagnetism, the singularity and the paradox of $4 / 3$ electrons. The complete system of equations of the electric circle always contains the number of equations equal to the number of unknowns. But if there are sections formed solely by the ideal sources of current $\mathbf{j}$ or contours formed entirely by the ideal sources of the voltage $e$, then it becomes undefined, since the equations, compiled according to Kirchhoff's laws for such intersections and contours (further called them EJ-degenerate) do not contain unknowns, although the laws themselves must be strictly adhered to.

Similar problems often occur in practice: enough to call the three-phase circle, the ideal voltage sources of which are connected by a triangle, or ideal sources of current - in the star. But most often EJdegeneration arises in the tasks of analysis of radio-electronic circles.

Scientific research often encounters practical problems whose solutions are simplified too much under the conditions of one or another local idealization, or even impossible without it. Therefore, one must be responsible to analyze the results obtained in each case. The problems of singularity were considered only in the sense of exacerbating the problem. Any mathematical image of a real physical process is carried out under one or another logical assumptions, including idealization. But idealization should use the discretion of .

Key words: idealization; singularity; EJ-degenerate circles; rotational singularity; harmonic electronic resonance; serial generator of constant current; non-conflict electron. 